\title{
Maksilla Anterior Bölgede Karbon Fiber Takviyeli Poli-Eter-Eter-Keton İmplantların Çevre Kemikte Oluşturduğu Streslerin Sonlu Elemanlar Analizi ile İncelenmesi
}

\author{
Investigation of Stress Levels at Surrounding Bone of Carbon Fiber Reinforced Polyether- \\ Ether-Keton Implants in the Maxilla Anterior Region with Finite Elemental Analysis
}

Sıdıka Sinem AKDENIZ ำ, Engin EDİBOĞLU

Öz

Amaç: Oral endoosseöz implantlar için ideal materyal seçimi; 1960'lı yılların sonuna doğru Branemark tarafından tanımlanan saf titanyumdur. Fakat tamamen metal içermeyen materyaller talep eden hastalar gün geçtikçe sayıca artmaktadır ve titanyumun bazı dezavantajları dolayısıyla dental implant için yeni materyal arayışları devam etmektedir. Çalışmamızın amacı geleneksel titanyum dental implantlara alternatif olarak kullanilabilecek CFR-PEEK materyalinin simüle edilecek oklüzyon kuvvetleri karşısında, implant çevresindeki kortikal ve spongioz kemikte meydana gelecek stresleri, sonlu eleman analizi ile inceleyerek klinik uygulamalara 1şık tutmaktır.

Materyal Metod:Bu çalışmada; maksiller santral diş bölgelerine yerleştirilen \%30 CFR-PEEK ve titanyum implantların okluzal kuvvetler karşısında, kortikal kemiğin en üst seviyesinde alınan referans noktalarında oluşturdukları stres değerleri, dağılımı ve yoğunlaşma bölgeleri incelendi. Araştırma üç boyutlu sonlu elemanlar stres analizi yöntemi ile statik lineer analiz yapılarak gerçekleştirildi.Analiz sonucunda, implant,implant çevresi kortikal kemikte ve spongioz kemikteki Von Misses, Maximum Principal; Minimum Principal stres değerlerine ve stres dağılımlarına bakılmıştır.

Bulgular: Çalışma sonucunda kortikal kemikte meydana gelen stresler, trabeküler kemikte meydana gelen streslerden yüksek bulundu. Oklüzal yükleme altında; implantlarda meydana gelen stres değerleri titanyum implant modelinde fazla iken, kemikte meydana gelen stresler CFR-PEEK implant olan modelde yüksektir.

Engin EDİBŎLU (ه)

Bahçelievler Mah. 11.sokak No:26 Başkent Üniversitesi Diş hekimliği fakültesi Çankaya/ANKARA

Tel: 0312.203.0000, Faks: 0312.246.6615

dtenginediboglu@gmail.com

Sidıka Sinem AKDENIZ

Başkent Üniversitesi Ağız Diş ve Çene Cerrahisi A.B.D.

Submitted / Gönderilme: 12.09.2019

Accepted / Kabul: 09.10.2019
Sonuç: CFR-PEEK implantların titanyum implantlara göre biyomekanik olarak bir avantajı bulunmamıștır. CFRPEEK implantların titanyum implantlara göre boyun kısmında kortikal kemikte non-homojen bir stres birikimine neden olduğu görülmüştür.

Anahtar Kelimeler: Cfr-Peek dental implant, anterior maksilla, sonlu elemanlar analizi

\begin{abstract}
Purpose: Ideal material selection for oral endoosseous implants as described by Branemark in the late 1960s was pure titanium. However, patients demanding completely non-metal materials and the search for new materials for dental implants continues due to some disadvantages of titanium. The aim of this study is to examine the stresses that will occur in the cortical and spongious bone around the implant against the occlusion forces of CFRPEEK material which can be used as an alternative to traditional titanium dental implants by using finite element analysis and to shed light on clinical applications.

Material and Method: The stress values, distribution and concentration zones of $30 \%$ CFR-PEEK and titanium implants placed at the maxillary central tooth regions at the reference points taken at the top level of the cortical bone were examined. The research was carried out by using static linear analysis with three-dimensional finite element stress analysis method. As a result of the analysis, von Misses, Maximum Principal; Minimum Principal stress values and stress distributions of dental implant and surronding bone were examined.

Results: As a result of the study, the stresses in the cortical bone were higher than the stresses in the trabecular bone. Under occlusal loading; the stress values in the implants are higher in the titanium implant model, whereas the stresses in the bone are higher in the CFR-PEEK implant model.

Conclusion: CFR-PEEK implants have no biomechanical advantage over titanium implants. CFR-PEEK implants were found to cause non-homogenous stress accumulation in the cortical bone in the neck compared to titanium implants.
\end{abstract}

\section{GíRiş}

Oral endoosseöz implantlar için ideal materyal seçimi; 1960’lı yılların sonuna doğru Branemark tarafindan 
tanımlanan saf titanyumdur(1). Ttitanyumdan veya Ti-6Al$7 \mathrm{Nb}$ ve Ti-6Al-4V gibi titanyum alaşımlarından üretilen dental implantlar bugüne kadar başarısı kanıtlanmış olmasına rağmen(2,3), kullanımlarının bir dizi sorun ile ilişkili olduğu ileri sürülmüştür. Bunlardan biri titanyumun potansiyel hipersensivite reaksiyonudur(4,5). Bir implantın ve çevresindeki kemiğin elastik modülleri arasındaki gradyan farklılıklar, başka problemlere de sebep olacaktır. Yükleme kuvvetlerinin meydana getirdiği implant-kemik arayüzündeki stres, implant çevresinde kemik kaybına yol açabilir(6). Bu fenomen, implantın uzun dönem başarısızlığ 1 ile direk olarak bağlantılı olabilir. Titanyumun 1 şık geçirgenliğinin az olması sebebiyle de estetik problemlere yol açabilir(7). Titanyum implant etrafında ince biyotipli mukoza varlı̆̆ında veya mukoza çekilmeleri sonucunda, mukoza da koyu bir renk görünümüne sebep olabilir. Bu da yüksek gülüş hattı olan kişilerde ciddi estetik problemler yaratabilir(8).

Tamamen metal içermeyen materyaller talep eden hastalar gün geçtikçe sayıca $\operatorname{artmaktadır(8).~Titanyuma~}$ alternatif olarak, 50 yıl önce tanımlanmış aliminyum oksitten oluşan seramik implantlar önerilmiştir. Fakat kırılma sıklığı insidansına göre, bu materyal implant materyali olarak titanyumun kullanılamayacağı durumlarda önerilmiştir. Zirkonyadan yapılmış seramik implantlar, diş benzeri rengi, mekanik özellikleri, biyomekanik özellikleri ve düşük plak affinitesi ile titanyuma daha iyi bir alternatif olarak gösterilmiştir(9). Zirkonyanın $210 \mathrm{GPa}$ değerindeki elastik modülü sebebiyle; zirkonya implantın, titanyum implanta göre implantı çevreleyen kemikte daha fazla strese yol açtığı gözlenmiştir(10).

Poli Eter Eter Keton(PEEK); 1978 y1lında geliştirilen organik sentetik polimerik bir materyaldir. PEEK; yüksek mekanik özelliklere ve kimyasal dirence sahip, biyouyumlu bir maddedir.Ayrıca üç boyutlu yazıcılar gibi modern görüntüleme teknolojileri ile çok uyumludur(11).

İmplant yerleştirildikten sonra marjinal kemik rezorpsiyonu çeşitli implant tipleri için bildirilmiştir. Daha az ortalama kemik kaybı da bildirilmiş olmasına rağmen, işlevsel yüklemenin ilk yılında yaklaşık $1 \mathrm{~mm}$ 'lik rezorpsiyonlar ve ardından yaklaşık yılda $0,1 \mathrm{~mm}$.' lik kemik kayb1 ile devam ettiği gözlenmiştir(12). Bu nedenle, bu dereceye kadar ortalama bir marjinal kemik rezorpsiyonu, stabil bir kemik seviyesi ve uzun süreli implant başarısı ile ilişkili görünmektedir.

İmplant etrafındaki kemik rezorpsiyonunun; genetik programlama, hormonal aktivite ve uygulanmış yük ile ilişkili olduğu belirtilmiştir. Treharne 1981 yılında biyomekanik ve morfoloji arasındaki ilişkiyi açıklayan konsept olan Wolf yasasını özetlemiştir. Bu yasa yüklenen karşısında kemik dokusunun remodelasyonu ve modelasyonunu doğrudan etkilediğini ve kemikte oluşan streslere karşı kemik şeklini ve formunu etkilemektedir(13). Bu fenomene dayanarak implantların uzun dönem başarısını değerlendirebilmek için, bir implanta gelecek kuvvetler karşısında implant materyalinin üzerinde ve çevresindeki kemikte olulabilecek streslerin değer ve dağılımları önemlidir(14).

Sonlu elemanlar analizi, yapısal mühendislik problemlerinin çözümünde yıllardan beri sayısal çözümleme amacıyla kullanılmaktadır. Bu yöntem ilk defa 1960' ların başlarında havacılık ve uzay endüstrisindeki yapısal problemlerin çözümü için geliştirilmiş ve o zamandan beri statik analiz, akışkanlar mekaniği, 1sı iletimi ve elektromanyetik analiz gibi birçok alanda ve diş hekimliğinde faydalı ve başarılı bir şekilde kullanılmaktadır. Diş hekimliğinde kullanılan materyallerin mekanik dayanıklılıklarının arttırılması ve dental yapılarda oluşan gerilmelerin belirlenmesi amacıyla, bu yapıların stres analizlerinin yapılması son yıllarda oldukça önem kazanmıştır. Sonlu elemanlar stres analizi çalışmaları, materyal özelliklerinin kuvvet altındaki davranışlarının incelenmesinde öncül analizleri oluşturmaktadır(15).

Çalışmamızın amacı geleneksel Titanyum dental implantlara alternatif olarak kullanılabilecek karbon fiber ile güçlendirilmiş polietereterketon(CFR-PEEK) materyalinin simüle edilecek oklüzyon kuvvetleri karşısında, implant çevresindeki kortikal ve spongioz kemikte meydana gelecek stresleri, sonlu eleman analizi ile inceleyerek klinik uygulamalara ışı tutmaktır.

\section{Materyal ve Metod}

$\mathrm{Bu}$ araştırma, Başkent Üniversitesi Tıp ve Sağlık Bilimleri Araştırma Kurulu tarafından onaylanmış (Proje No: DA 19/04) ve Başkent Üniversitesi Araştırma Fonunca desteklenmiştir.

$\mathrm{Bu}$ çalışmada; maksiller santral diş bölgelerine yerleştirilen \%30 CFR-PEEK ve titanyum implantların okluzal kuvvetler karşısında, kortikal kemiğin en üst seviyesinde alınan referans noktalarında oluşturdukları stres değerleri, dağılımı ve yoğunlaşma bölgeleri incelendi. Araştırma üç boyutlu sonlu elemanlar stres analizi yöntemi ile statik lineer analiz yapılarak gerçekleştirildi. 


\section{Üç Boyutlu Modelleme}

\section{Kemik modellerinin oluşturulması}

Kemik dokularının modellenmesi için, öncelikle tam dişsiz erişkin bir hastanın tomografisi çekildi. Tomografi çekiminde 3M Iluma CBCT cihazı kullanıldı. Çekimde $120 \mathrm{KvP} 3.8 \mathrm{~mA}$ değerlerinde 40 saniyelik çekim modu kullanıldı. Çekilen filmler, 3d-doctor yazılımına atıldı ve burada "Interactive Segmentation" yöntemi ile Hounsfield değerlerine bakılarak kemik dokusu ayrıştırıldı. Yapılan ayrıştırma işleminden sonra " $3 \mathrm{~d}$ Complex Render" yöntemi ile 3 boyutlu model elde edildi ve bu şekilde kemik dokusu modellenmiş oldu. Kemik dokusundan ofset yöntemi ile spongioz kemik elde edildi ve gerekli uyumlamaların yapılması ile kuvvet aktarımı sağlanmış oldu. Bu şekilde mandibula ve maksillanın molar bölgelerinde kortikal kemik, spongioz kemik gerçek morfolojisini yansıtacak biçimde modele taşındı.

\section{İmplant ve protez parçalarının modellerinin oluşturulması}

Çalışmada tedarik edilen implant ve protez parçaları SmartOptics 3 boyutlu tarayıcisı ile 3 boyutlu olarak tarand1. .stl formatında elde edilen modeller, Rhinoceros 4.0 (3670 Woodland Park Ave N, Seattle, WA 98103 USA) yazılımına gönderildi. Rhino yazılımında Boolean yöntemi ile protez alt ve üst parçaları, implant vidaları ve kemik dokuları arasında uyumlandırma yapıldı ve kuvvet aktarımı sağlandı.

Çalışmanın gerçekçi sonuçlar vermesi için programın el verdiği ölçüde, seçtiğimiz çene kemiğinin modelinin boyutlarını göz önüne alarak mümkün olduğunca fazla eleman sayısı seçilmiştir. Senaryoları içeren matematiksel modellerde kullanılan eleman ve düğüm sayıları aşağıda verilmiş̧ir:

Düğüm sayıs1 $=25421$

Eleman say1s1 $=127867$

Modeller Algor yazılımı ile uyumlu hale getirildikten sonra, oluşturulan modelin, kemik ve implant yapılarının hangi materyalden yapıldığını yazılıma tanıtmak gerekmektedir. Modelleri oluşturan yapıların her birine, fiziksel özelliklerini tanımlayan materyal (elastiklik modülü ve Posison oranı) değerleri Tablo 1' de verilmiş̦tir.
Tablo 1: İmplant materyallerinin ve kemik dokusunun fiziksel özelliklerini tanımlayan 'Young Modülü' ve 'Poisson Ratio' değerleri

\begin{tabular}{|l|l|l|}
\hline Materyaller & Young Modülü (MPa) & Poisson Ratio \\
\hline Kortikal(16) & 17400 & 0.30 \\
\hline Sponge - D3(17) & 1600 & 0.30 \\
\hline Feldspatik porselen(18) & 69000 & 0.30 \\
\hline Titanyum(19) & 110000 & 0.35 \\
\hline Cfr-Peek(20) & 18000 & 0.39 \\
\hline
\end{tabular}

Bu şekilde maksillada kortikal kemik, spongioz kemik, protez, alt yapı parçaları ve implantlar gerçek morfolojisini yansıtacak biçimde modele taşındı. (Şekil 1)

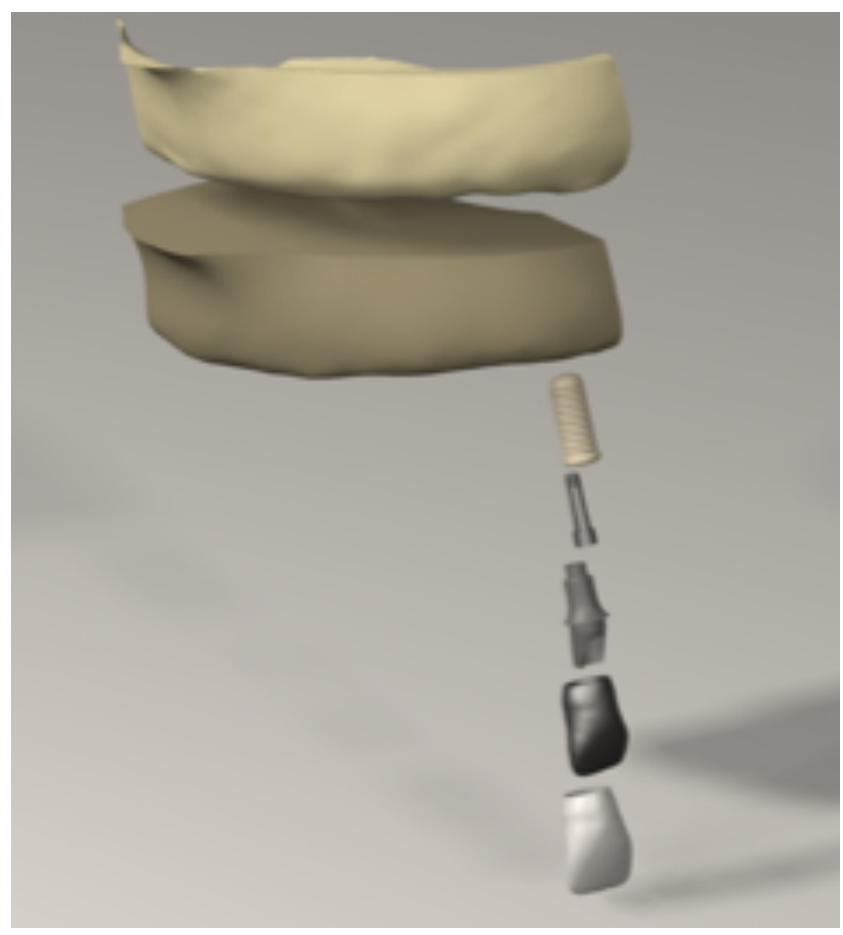

Şekil 1: Maksillada kortikal kemik ve spongioz kemik; implant, implant ara parçaları ve protezinin üç boyutlu modellenmesi

Yapılan modellemeler Rhinoceros yazılımında modeller 3 boyutlu uzayda doğru koordinatlara yerleştirildi ve modelleme işlemi tamamlanmış oldu. Rhino'da yapılan modellemeler, 3 boyutlu koordinatlar korunarak Fempro yazılımına aktarıldı. Model çene kemiğinin alt ve arka kısmindan her DOF (Degree of freedom)'da 0 harekete sahip olacak şekilde sabitlenmiştir.

3 boyutlu ağ yapısının düzenlenmesi ve daha homojen hale getirilmesi, 3 boyutlu katı modelin oluşturulması ve sonlu elemanlar stres analizi işlemi için Intel Xeon ${ }^{\circledR}$ R CPU 3,30 GHz işlemci, 500gb Hard disk, 14 GB RAM donanımlı ve Windows 7 Ultimate Version Service Pack 
1 işletim sistemi olan bilgisayardan, Activity 880 (smart optics Sensortechnik GmbH, Sinterstrasse 8, D-44795 Bochum, Almanya) optik tarayıcısı ile 3 boyutlu taramadan, Rhinoceros 4.0 (3670 Woodland Park Ave N, Seattle, WA
98103 USA) 3 boyutlu modelleme yazılımından, VRMesh Studio (VirtualGrid Inc, Bellevue City, WA, USA) ve Algor Fempro (ALGOR, Inc. 150 Beta Drive Pittsburgh, PA 15238-2932 USA) analiz programından yararlanılmıştır.

Tablo 2: İki farklı implant materyali ile oluşturulan modellere verilen kuvvetler sonucunda implant, kortikal kemik ve spongioz kemik üzerinde oluşan stres değerleri

\begin{tabular}{|c|c|c|c|c|c|c|c|}
\hline $\begin{array}{l}\text { İmplant } \\
\text { Materyal }\end{array}$ & $\begin{array}{l}\text { Verilen } \\
\text { Kuvvet }\end{array}$ & $\begin{array}{l}\text { İmplant VonMisses } \\
\qquad\left(\mathrm{N} / \mathrm{mm}^{2}\right)\end{array}$ & $\begin{array}{l}\text { Kortikal Max. } \\
\text { Principle } \\
\text { (Gerilme Stresi) } \\
\left(\mathrm{N} / \mathrm{mm}^{2}\right)\end{array}$ & $\begin{array}{l}\text { Kortikal Min. } \\
\text { Principle } \\
\text { (Sıkışma Stresi) } \\
\left(\mathrm{N} / \mathrm{mm}^{2}\right)\end{array}$ & $\begin{array}{l}\text { Sponge Max. } \\
\text { Principle( } \\
\text { Gerilme Stresi) } \\
\left(\mathrm{N} / \mathrm{mm}^{2}\right)\end{array}$ & $\begin{array}{c}\text { Sponge Min. } \\
\text { Principle } \\
\text { (S1k1şma Stresi) } \\
\left(\mathrm{N} / \mathrm{mm}^{2}\right)\end{array}$ & $\begin{array}{c}\text { Sponge Min.Principle } \\
\text { Apikal(Sıkışma Stresi) } \\
\left(\mathrm{N} / \mathrm{mm}^{2}\right)\end{array}$ \\
\hline Titanyum & $100 \mathrm{~N}$ & 180,267459 & 25,05256 & $-34,0577$ & 2,570131 & $-1,142649$ & $-1,180684$ \\
\hline $\begin{array}{l}\text { \%30 Cfr- } \\
\text { Peek }\end{array}$ & $100 \mathrm{~N}$ & 88,536639 & 31,09588 & $-41,208518$ & 4,881815 & $-2,027488$ & $-0,46649$ \\
\hline
\end{tabular}

\section{Bulgular}

$\mathrm{Bu}$ çalışmada, maksilla santral bölgeye yerleştirilmiş farklı materyallerden oluşan 2 implantın üzerinde ve çevre kemik üzerinde oklüzal kuvvetlere karş1 oluşan stresin ölçülmesi planlanmıştır. Silindirik şekilli $(4.1 \mathrm{~mm}$. x 10 mm. boyutlarında) \%30 karbonfiber ile güçlendirilmiş polietereterketon (CFR-PEEK) ve titanyumdan meydana gelen 2 implant değerlendirilmiştir. Lekholm-Zarb kemik sınıflamasında yer alan tip 3 kemiğe yerleştirilmiş bu implantların palatinalinden 45 derece açı ile 100 Newton'luk kuvvet uygulanmıştır. Bu kuvvetin implantta, kortikal kemikte ve spongioz kemikte olmak üzere 3 farklı bölgede yarattı̆̆ Von Misses, Maximum Principal ve Minimum Prinsipal stres değerleri Tablo 2 de verilmiştir.. Analiz sonuçlarında artı değerler gerilme streslerini, eksi değerler ise sıkışma streslerini belirtmektedir. Bir stres elemanında hangi stres tipinin mutlak değeri daha büyük ise, stres elemanı o stres tipinin etkisi altındadır ve değerlendirilmesi gerekende o stres tipidir.
İmplantların üzerinde oluşan Von Misses değerleri karşılaştırıldığında; titanyum implantta oluşan en yüksek Von Misses stres değeri, CFR-PEEK implantta oluşan en yüksek Von Misses stres değerine göre daha yüksektir.

Kemik dokusunda; kortikal kemikte ve spongioz kemikte ayrı olacak şekilde en yüksek gerilme ve sıkışma stresleri tabloda gösterilmiştir. Kortikal kemikte ve spongioz kemikte; CFR-PEEK implantların oluşturduğu en yüksek stres değerleri hem sıkışma hem de gerilme streslerinde, titanyum implanların kemik üzerinde oluşturduğu stres değerlerinden yüksektir.

Kortikal kemik üzerindeki gerilme stresleri ve sıkışma streslerinin dağılımına bakıldığ 1 zaman; implantın palatinalinde gerilme streslerinin ve bukkalindeki sıkışma streslerinin yoğunlaştığı görülüyor. Her iki implant da hem sıkışma hem gerilme streslerini; kortikal kemik üzerinde benzer bir şekilde homojen dağıttığı görülmektedir(Şekil 2).

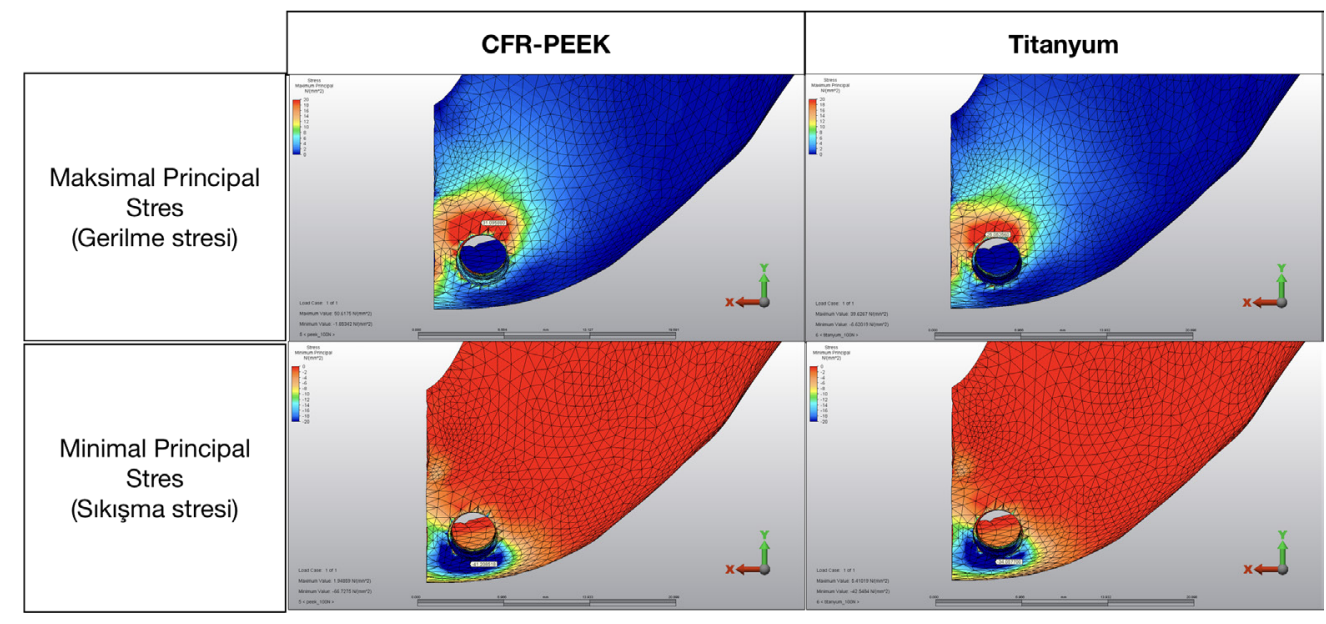

Şekil 2: CFR-PEEK implant ve titanyum implantın kortikal kemik üzerinde oluşturduğu gerilme ve sıkışma stresleri 
Spongioz kemik üzerinde ise gerilme ve sıkışma streslerine bakıldığı zaman; CFR-PEEK implant, kemiğin bukkal bölgesinde hem nicelik olarak hem de nitelik olarak titanyuma göre daha yüksek streslere sebep olmuştur.
Her iki materyalden meydana gelen implantların apikal bölgelerindeki spongioz kemikte oluşan sıkışma stresleri incelendiğinde; CFR-PEEK implant, titanyum implanta göre daha az sıkışma stresi meydana getirmiştir.(Şekil 3)

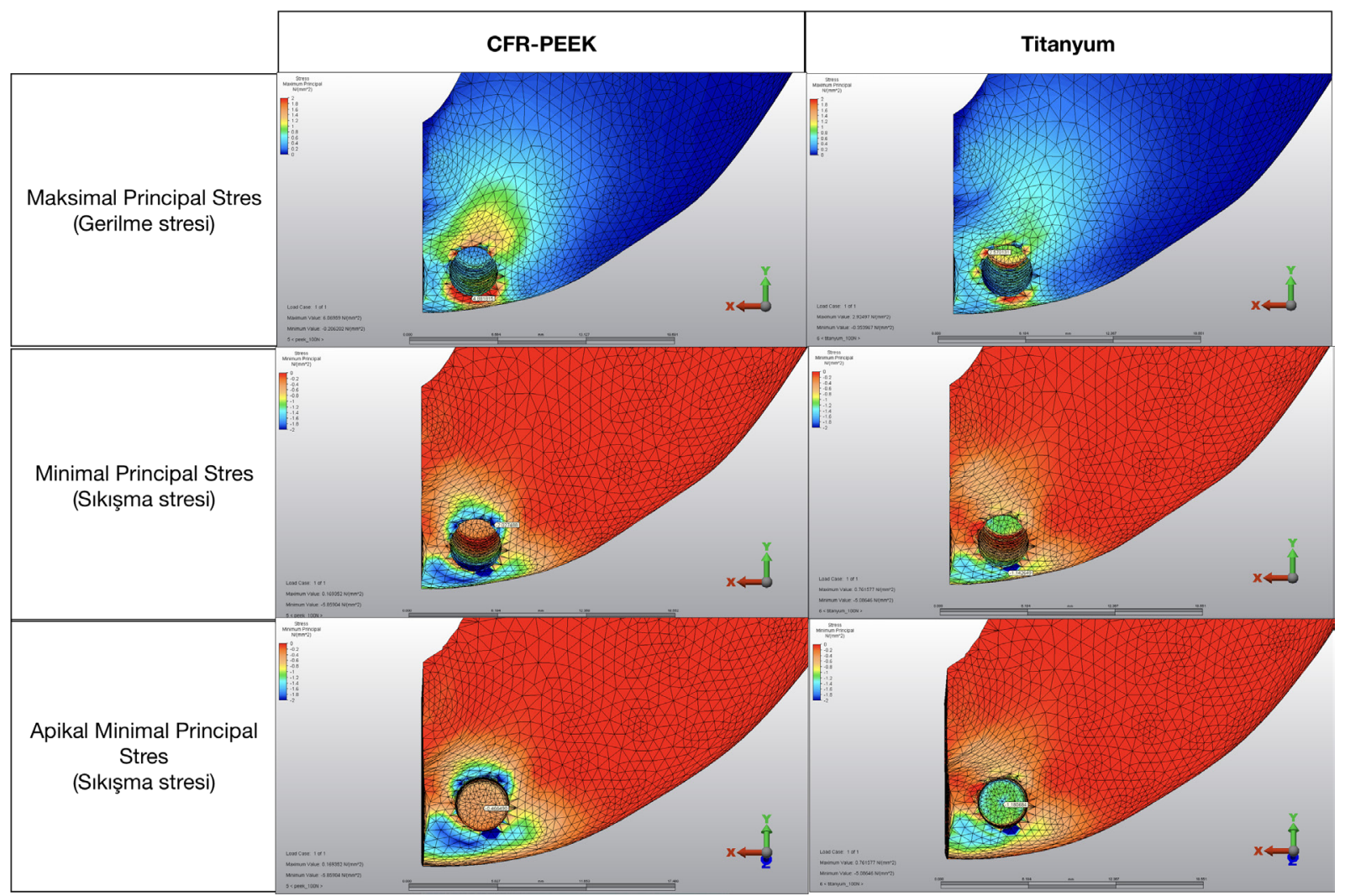

Şekil 3: CFR-PEEK implantın ve titanyum implantın spongioz kemik üzerinde oluşturduğu gerilme ve sıkışma stresleri

\section{Tartışma}

PEEK polimer ailesinin ümit verici mekanik özellikleri, implantların şekil ve uygulamalarındaki muazzam çok yönlülüğe bağlı olarak 1990'lardan bu yana büyük ilgi gösterilmesine neden oldu. Bu gelişmelere kadar, tıpta elde edilen en iyi sonuçlar ortopedi anabilim dalında özellikle omurga alanında, intervertebral stabilizasyon için kafeslerin kullanılması ile bildirilmiştir(21). Diğer çalışmalar(22-24) ,ortopedik hastalarda bu polimerin olumlu klinik performansını göstermiştir. Bu sonuçlar,\% 30 karbon fiber ile güçlendirilmiş PEEK' in bir özelliği olan elastik modülün kemiğe benzerliği ile açıklanır. Bu nedenle, bu çalışmada, araştırma için CFR-PEEK seçilmiş̧ir.

Modellerin şeklindeki farklılıkların olmamasından dolayı, araştırma malzemelerin mekanik özelliklerinin değerlendirilmesine odaklanmıştır. İmplant çevresindeki kemik üzerinde kontrollü veya standart yüklerin etkisi ile ilgili randomize klinik çalışma bulunmamaktadır. Okluzal yüklerin doğal yönünün ve sayısal değerinin klinik ölçümü kesinlikle zordur(25). Kemik dokusunun, sıkıştırma yüklerine daha dayanıklı, gerilme yüklerine daha az dirençli ve kesme yüklerine daha az dirençli olduğu bilinmektedir(26). Bununla birlikte, implantın işlevini ve kemik remodelasyonu göz önünde bulundurarak, ilgili yük parametrelerinin belirlenmesi, belki de en önemli süreçtir, bu işlemdeki gerilme ve sıkıştırma yüklerinin belirgin etkisi tam olarak araştırılmamıştır.

Farkl1 modellerdeki implant boynundaki stres yoğunluklarının eğilimini, daha önce de yapılmış çalışmalarla kabul görmüş olan Von Misses stres değerinin hem nicelik olarak hem nitelik olarak değerlendirilmesiyle belirlenir(19,20). Bu çalışmada titanyum implanttaki Von Misses stres değeri, CFR-PEEK implanttaki Von Misses stres değerinden daha yüksek olmasına rağmen CFR-PEEK 
implantta oluşan stres, titanyum implantta oluşan strese göre daha yıkıcı olabilir. Bunun da sebebi; 120Mpa. gerilme dayanımına sahip CFR-PEEK materyalinin, $954 \mathrm{MPa}$. gerilme dayanımına sahip titanyum gibi bir materyale göre, streslere karşı daha dayanıksız olmasıyla açıklanabilir.
Ayrıca implantların üzerindeki stres dağılımları incelendiği zaman titanyumun yüksek stresli bölgeleri daha geniş alanda ve homojen bir şekilde karşılarken, CFR-PEEK implantta ise yüksek stres boyun bölgesinde yoğunlaşmıştır. (Şekil 4)

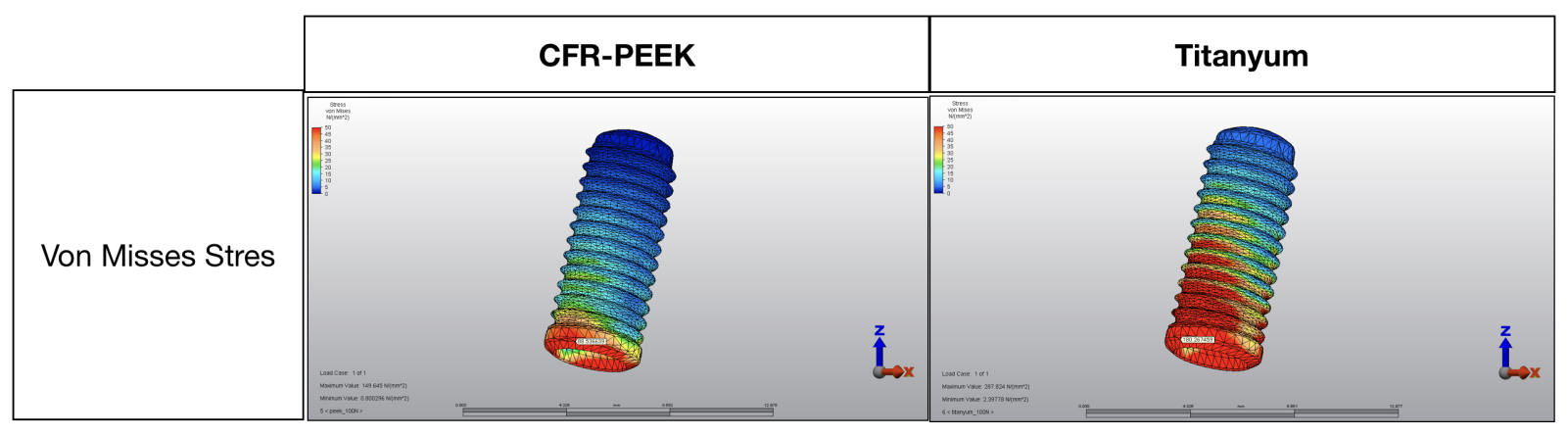

Şekil 4: CFR-PEEK implant ve titanyum implant üzerindeki Von Misses stresleri

Biyomekanik özellikler, osseoentegre implantların uzun dönemdeki başarısında en önemli faktörlerdir. Fonksiyonel kuvvetler sırasında oluşan biyomekanik gerilim ve gerinimler kemiğin remodelasyonunu etkilemektedir(27-29). İmplant destekli protezlerin başarısında oklüzal kuvvetlere ait biyomekanik faktörlerin in vivo çalışmalarla tespit edilmesi imkansızdır(30). Bu sebeple implantların uzun dönem başarısını yorumlayabilmek için sonlu elemanlar analizinin önemi büyüktür. Çiğneme kuvvetleri implant üst yapıları ve abutmentlar aracılığıyla, öncelikle implantlara, implantlar aracılığıyla ise kemiğe iletilmektedir(15). Bu nedenle implant materyallerinin elastik modülü implant - kemik arayüzünü ve kemiğe iletilen stres miktarını etkilemektedir(29). Değişik elastik modüle sahip implant materyalleri, stres iletiminde farklılık göstermektedir. $\mathrm{Bu}$ çalışmadaki modellerde kullanılan CFR-PEEK materyalinin, materyal özelliklerinin kemiğe benzer olması ve ortopedideki kullanımının pozitif sonuçları sebebiyle, kemik üzerinde daha az stres oluşturması beklenirken; titanyum implant gelen kuvvetleri, CFR-PEEK materyali ne göre daha düşük bir stres değeri ile daha homojen bir şekilde kemiğe iletmiştir.

$\mathrm{Bu}$ çalışmanın sonlu elemanlar analizi sonuçları, CFRPEEK implantın başarısı hakkında bize her ne kadar yorum yapma şansı vermiş olsa da, klinik ve hayvan çalışmalarıyla incelenmesi gerekmektedir.

\section{Sonuç}

CFR-PEEK materyalinin; biyouyumlu, kemiğe yakın mekanik özelliklere sahip olması, ortopedideki başarılı kullanımı ve üretim kolaylığı gibi avantajlara sahip olması, titanyuma alternatif olabilecek bir dental implant materyali olarak düşünülmüştür. Fakat yapılan sonlu eleman analizleri sonucunda, maksilla anterior bölgede, implantta ve çevre kemikte oluşturdukları stres bakımından CFR-PEEK dental implantlarının, titanyum implantlara göre biyomekanik bir avantajı bulunamamıştır.

\section{Referanslar}

1. Brånemark P. I., Breine U., Adell R., et al. Intra-osseous anchorage of dental prostheses: I. Experimental studies. Scand. J. Plast. Reconstr. Surg. Hand Surg. 3, 81-100 ,1969.

2. Shapira Lior, Klinger Avigdor, Tadir Anat, et al. Effect of a niobium-containing titanium alloy on osteoblast behavior in culture. Clin. Oral Implants Res. 20, 578-582,2009.

3. Velasco-Ortega Eugenio, Jos Angeles, Cameán Ana M., et al. In vitro evaluation of cytotoxicity and genotoxicity of a commercial titanium alloy for dental implantology. Mutat. Res. - Genet. Toxicol. Environ. Mutagen. 702, 17-23 ,2010.

4. Egusa Hiroshi, Ko Nagakazu, Shimazu Tsunetoshi, et al. Suspected association of an allergic reaction with titanium dental implants: A clinical report. J. Prosthet. Dent. ,2008. doi:10.1016/S0022-3913(08)60233-4

5. Müller Kurt, Valentine-Thon Elizabeth. Hypersensitivity to titanium: clinical and laboratory evidence. Neuro Endocrinol. Lett. ,2006.

6. Huiskes R, Weinans H, van Rietbergen B. The relationship between stress shielding and bone resorption around total hip stems and the effects of flexible materials. Clin. Orthop. Relat. Res. ,1992.

7. Yildirim Murat, Fischer Horst, Marx Rudolf, et al. In vivo fracture resistance of implant-supported all-ceramic restorations. J. Prosthet. Dent. 90, 325-331,2003. 
8. Andreiotelli Marina, Wenz Hans J., Kohal Ralf Joachim. Are ceramic implants a viable alternative to titanium implants? A systematic literature review. Clinical Oral Implants Research 20, 32-47,2009.

9. Özkurt Zeynep, Kazazoğlu Ender. Zirconia Dental Implants: A Literature Review. J. Oral Implantol. 37, 367-376,2010.

10. Özkurt Zeynep, Kazazoĝlu Ender. Clinical success of zirconia in dental applications. J. Prosthodont. 19, 64-68,2010.

11. Schwitalla Andreas, Müller Wolf-Dieter. PEEK Dental Implants: A Review of the Literature. J. Oral Implantol. 39, 743-749,2011.

12. Goodacre C J, Kan J Y, Rungcharassaeng K. Clinical complications of osseointegrated implants. J. Prosthet. Dent. 81, 537-52,1999.

13. RW. Treharne. Review of Wolff's law and its proposed means of operation. Orthop Rev. 10, 35-47,1981.

14. Wiskott H. W. Anselm, Belser Urs C. Lack of integration of smooth titanium surfaces: a working hypothesis based on strains generated in the surrounding bone. Clin. Oral Implants Res. 10, 429-444,2003.

15. van Staden R. C., Guan H., Loo Y. C. Application of the finite element method in dental implant research. Computer Methods in Biomechanics and Biomedical Engineering 9, 257-270,2006.

16. Geng J. P., Ma Q. S., Xu W., et al. Finite element analysis of four thread-form configurations in a stepped screw implant. J. Oral Rehabil. 31, 233-239,2004.

17. Sevimay M., Turhan F., Kiliçarslan M. A., et al. Threedimensional finite element analysis of the effect of different bone quality on stress distribution in an implant-supported crown. J. Prosthet. Dent. 93, 227-234,2005.

18. Meyer Ulrich, Vollmer Dirk, Runte Christoph, et al. Bone loading pattern around implants in average and atrophic edentulous maxillae: A finite-element analysis. J. CranioMaxillofacial Surg. 29, 100-105,2001.

19. Koca Omer Lutfi, Eskitascioglu Gurcan, Usumez Aslihan. Three-dimensional finite-element analysis of functional stresses in different bone locations produced by implants placed in the maxillary posterior region of the sinus floor. J. Prosthet. Dent. 93, 38-44,2005.
20. Zampelis Antonios, Rangert Bo, Heijl Lars. Tilting of splinted implants for improved prosthodontic support: A two-dimensional finite element analysis. J. Prosthet. Dent. 97, 535-543,2007.

21. Kurtz Steven M., Devine John N. PEEK biomaterials in trauma, orthopedic, and spinal implants. Biomaterials 28, 4845-4869,2007.

22. Toth Jeffrey M., Wang Mei, Estes Bradley T., et al. Polyetheretherketone as a biomaterial for spinal applications. Biomaterials 27, 324-334,2006.

23. Brantigan John W., Neidre Arvo, Toohey John S. The Lumbar I/F Cage for posterior lumbar interbody fusion with the Variable Screw Placement System: 10-year results of a Food and Drug Administration clinical trial. Spine J. 4, 681688,2004 .

24. Akhavan Sam, Matthiesen Mary M., Schulte Leah, et al. Clinical and histologic results related to a low-modulus composite total hip replacement stem. J. Bone Jt. Surg. - Ser. A 88, 1308-1314,2006.

25. Isidor Flemming. Influence of forces on peri-implant bone. Clin. Oral Implants Res. 17, 8-18,2006.

26. Misch Carl E., Suzuki Jon B., Misch-Dietsh Francine M., et al. A positive correlation between occlusal trauma and periimplant bone loss: Literature support. Implant Dent. 14, 108116,2005 .

27. Albrektsson T, Zarb G, Worthington P, et al. The long-term efficacy of currently used dental implants: a review and proposed criteria of success. Int. J. Oral Maxillofac. Implants 1, 11-25, 1986 .

28. Şahin Saime, Çehreli Murat C., Yalçin Emine. The influence of functional forces on the biomechanics of implantsupported prostheses - A review. Journal of Dentistry 30, 271-282,2002.

29. Geng Jian Ping A., Tan Keson B.C., Liu Gui Rong. Application of finite element analysis in implant dentistry: A review of the literature. Journal of Prosthetic Dentistry 85, 585-598,2001.

30. Sato Y., Teixeira E. R., Tsuga K., et al. The effectiveness of a new algorithm on a three-dimensional finite element model construction of bone trabeculae in implant biomechanics. J. Oral Rehabil. 26, 640-643,1999. 